PS07.02.14 CRYSTAL STRUCTURE AND EPR DATA OFA DINUCLEAR Cu(II) COMPLEX, [Cu(N $\left.{ }_{3}\right)(\mathrm{NCO})$ diEten] ${ }^{2}$. J. Zukerman-Schpector, ${ }^{1}$ O.E. Piro, 2 E.E. Castellano, ${ }^{3}$ C.A. De Simone, ${ }^{4}$ D.M. Martino5 and C.A. Steren 51 Dept. Qumica, Univ. Federal de Sao Carlos. C.P. 676, 13565-905 Sao Carlos(SP), Brazil, 2Dept. Fisica, Ftad. C. Exactas, Univ. Nacional de La Plata, C.C. 67, 1900 La Plata, Argentina 3Inst. Fisica de Sao Carlos, Univ. de Sao Paulo, C.P. 369, 13560 Sao Carlos, Brazil 4Dept. Quimica, Univ. Federal de Alagoas, 57000 Maceio (AL), Brazil, 5INTEC (CONICET-UNL), Guemes 3450, 3000 Santa Fe Argentia

The $\left[\mathrm{Cu}\left(\mathrm{N}_{3}\right)(\mathrm{NCO})\left(\mathrm{C}_{16} \mathrm{~N}_{2}\right)\right]_{2}$ molecules are arranged as centrosymmetric dimers in which two azide ligands bridge neighboring copper ions in an asymmetric head-on fashion. The $\mathrm{Cu}(\mathrm{II})$ ion is coordinated to five nitrogen atoms which form a distorted tetragonal pyramid. At the pyramid base are the two $\mathrm{N}$ atoms of a diEten molecule $[\mathrm{d}(\mathrm{Cu}-\mathrm{N})=2.00(1), 2.12(1) \AA]$, an azide end atom $[\mathrm{d}(\mathrm{Cu}-\mathrm{N})=1.99(1) \AA]$ and a $\mathrm{NCO}$ group $[\mathrm{d}(\mathrm{Cu}-\mathrm{N})=1.95(1) \AA]$. At the pyramid apex is the other, inversion related to the first one, azide $\mathrm{N}$ atom in the dimer $[\mathrm{d}(\mathrm{Cu}-$ $N)=2.38(1) \AA]$. This Cu-N contact links the monomers within a dimer providing a electronic path to transmit the superexchange coupling between the $\mathrm{Cu}(\mathrm{II})$ unpaired electrons. Neighboring dimers are coupled y weak N-H..O contacts. Single crystal EPR data at X-band show that the pair of resonances expected for neighboring, magnetically nonequivalents dimers, collapse into a single line, a signature of interdimers superexchange coupling. The observed crystal gyromagnetic tensor is used to disclose the electronic and magnetic structure around $\mathrm{Cu}(\mathrm{II})$ ions. The compound crystallizes in the space P21/n, with $a=8.336(1)$, $b=17.405(3), c=8.376(1) \AA, \beta=109.73(2)^{\circ}$ and $Z=4$.

\section{Metal Clusters}

PS07.03.01 CRYSTAL STRUCTURE OF 6,9-BIS(4STLBAZOLE)-NIDO-DECABORANE(12), 6,9-[4-( $\left.\mathrm{PhC}_{2} \mathrm{H}_{2}\right)$ $\mathrm{Py}_{2} \mathrm{~B}_{10} \mathrm{H}_{12}$. V.I.Alekseev, T.M. Polyanskaya, S.T.Dunaev, E.A.I' inchik, Institute of Inorganic Chemistry Sib. Branch RAS, Novosibirsk, Russia

A single-crystal $X$-ray study has been performed for the title decaborane(14) derivative. The sample used was prepared by the well known type of displacement reaction of $\left(\mathrm{SMe}_{2}\right)_{2} \mathrm{~B}_{10} \mathrm{H}_{12}$ with 4-stilbazole and was recrystallized from hot dimethylformamide.

The most interesting feature of the compound is that four crystallographically independent asymmetrical molecules exist in the unit cell due to different arrangements of both the two cycle aromatic pyridine and phenol fragments and those in respect to the three-dimensional aromatic $\mathrm{B}_{10} \mathrm{H}_{12}$ nido-cluster.

The nitrogen atoms of pyridine are linked to the 6,9-boron atoms on the open face of the $B_{10}$ basket at the mean distance of $1.60 \AA$. The following mean bond lengths are B-B 1.80, C-N 1.33, $\mathrm{C}-\mathrm{C} 1.40$ and $1.38 \AA$ for $\mathrm{Py}$ and $\mathrm{Ph}$, respectively.

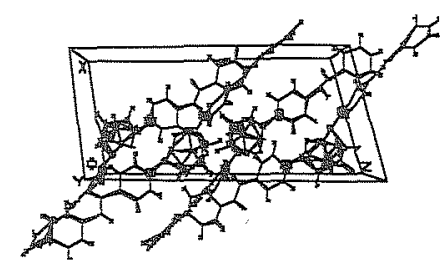

Crystal data: dark red color, triclinic P1, $a=11.285(1), b=13.061(2)$, $c=21.176(2) \AA, \alpha=85.37(1), \beta=102.26(1), \gamma=115.58(1)^{\circ}$, $V=2750.7(7) \AA 3, Z=4, D_{c}=1.165 \mathrm{~g} \cdot \mathrm{cm}^{-1}, C A D-4, \lambda$ MoK $\alpha$.

As a solid, this compound exhibites a photoluminescence $\left(\lambda_{\mathrm{f}}=653 \mathrm{~nm}\right)$ with the quantum yield approximating that of rhodamine $6 \mathrm{G}$.
PS07.03.02 INCOMPLETE CUBANES $\mathrm{M}_{3} \mathrm{X}_{4}{ }^{4+}$. Alan Hazella, Michael Brorson, Claus Jacobsen ${ }^{b}$, Birgitte Jespersen ${ }^{b}$ and Iver Schmidtb aChemistry Dept. Aarhus University, DK-8000 Århus C, Denmark. bHaldor Topsøe A/S, Nymøllevej 55, DK2800 Lyngby, Denmark.

Cluster compounds of the type $\mathrm{M}_{3} \mathrm{X}_{4}^{4}$ and $\mathrm{M}_{3} \mathrm{X}_{4} \mathrm{M}^{\prime} 4+\mathrm{M}=\mathrm{Mo}, \mathrm{W}$; $\mathrm{X}=\mathrm{O}, \mathrm{S} ; \mathrm{M}^{\prime}=\mathrm{CO}, \mathrm{Ni}, \mathrm{Fe}$ ) are being studied as catalysts for homogeneous hydrosulphurization e.g.

$$
\mathrm{C}_{4} \mathrm{H}_{8} \mathrm{~S}+2 \mathrm{H}_{2} \rightarrow \mathrm{C}_{4} \mathrm{H}_{10}+\mathrm{H}_{2} \mathrm{~S}
$$

The structures of two such compounds have been studied:

$1\left(\mathrm{NH}_{4}\right)_{4 \times \mathrm{x}} \mathrm{K}_{\mathrm{x}}\left[\mathrm{MO}_{3} \mathrm{O}_{4}(\mathrm{CHOO})_{8} \cdot\left(\mathrm{H}_{3} \mathrm{O}\right) \cdot(\mathrm{CHOO}) \cdot \mathrm{H}_{2} \mathrm{O}(\mathrm{x}=0.80)\right.$ and $2 \mathrm{~K}_{5}\left[\mathrm{~W}_{3} \mathrm{~S}_{4}(\mathrm{CHOO})_{9}\right]^{\circ}(\mathrm{CHOO}) \cdot 3 \mathrm{H}_{2} \mathrm{O}$.

1 is triclinic, space group P-1 with $a=11.011(2), b=13.310(2), c$ $=9.993(1) A, \alpha=106.817(7), \beta=91.651(9), \gamma=88.340(9)^{\circ}, Z=2, R(F)=$ 0.026 for $N_{0}=3972$ and $N_{v}=451.2$ is monoclinic, space group $C 2 / m$ with $\mathrm{a}=19.606(6), \mathrm{b}=14.348(7), \mathrm{c}=13.627(5) \AA$ and $\mathrm{B}=118.94(2)^{\circ}, \mathrm{Z}$ $=4, R(F)=0.049$ for $N_{0}=2656$ and $N_{V}=226$.

1 contains isolated $\left[\mathrm{Mo}(\mathrm{iv})_{3} \mathrm{O}_{4}(\mathrm{CHOO})_{8}\right]^{4}$ anions with one of the formate ions bridging two molybdenum atoms whereas in 2 all nine monodentate formate ions are bound to a $\mathrm{W}(\mathrm{iv})_{3} \mathrm{~S}_{4}$ cluster. In both compounds there is a free formate ion. In 1 two of the cation sites are disordered and are occupied by either potassium or ammonium ions. 2 is either disordered or has a lower symmetry than $\mathrm{C} 2 / \mathrm{m}$, but refinement in lower symmetry space groups did not give a lower $\mathrm{R}$-value.
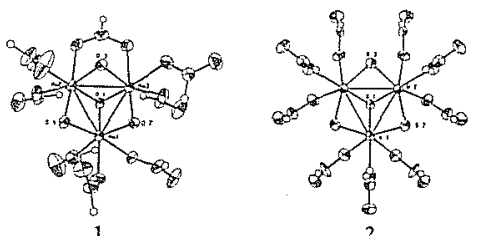

PS07.03.03 SYNTHESIS AND STRUCTURE OF DI- $\mu-$ ACETATOBIS [DICARBONYLPYRAZOLERUTHENIUMI(I)] (Ru-Ru) By C. H. Huang', T. H. Lu' ${ }^{1}$, W. M. Lee? and K. B. Shiu' 1 Department of Physics, National Tsing Hua University, Hsinchu, Taiwan, 300; 2 Department of Chemistry, National Cheng Kung University, Tainan, Taiwan 701, Republic of China.

Nucleophilic substitution of $\left[\mathrm{Ru}_{2}(\mathrm{CO})_{4}\left(\mu-\mathrm{O}_{2} \mathrm{CMe}\right)_{2}(\mathrm{NCMe})_{2}\right]$ with excess pyrazole $(\mathrm{HPz})$ gave almost quantitatively the title compound $\left[\mathrm{RU}_{2}(\mathrm{CO})_{4}\left(\mu-\mathrm{O}_{2} \mathrm{CMe}\right)_{2}(\mathrm{Hpz})_{2}\right]$.

$\mathrm{X}$-ray sttucture of the compound was determined after crystal dimensions of $0.30 \times 0.35 \times 0.45 \mathrm{~mm}$ had been selected. The cell dimensions are $a=8.332(1), b=9.5236(7), c=13.539(2) \AA, \alpha=90.020(8)$, $\beta=100.33(2), \gamma=111.34(1)^{\circ}$ with centrosymmetric space group of $P 1$ bar. The cell volume is $982.0(2) \AA^{3}$ containing two molecules. Calculated density is $1.922 \mathrm{Mg} \mathrm{m}^{-3}$. The linear absorption coefficient of the crystal is $1.55 \mathrm{mmm}^{-1}$. Absorption corrections were made. The final R/Rw factors were $0.026 / 0.042$ for 3886 reflections with $\mathrm{D} 2.5 \sigma$ (I) collected on a Nonius diffractometer, using the theta/ two theta scan mode. Weights based on counting-statistics were used. The maximum shift/sigma ratio was 0.001 . In the last difference Fourier map, the deepest hole was $-.54 \mathrm{e} / \AA^{3}$ and the highest peak $0.88 \mathrm{e} / \AA^{3}$. The secondary extinction coefficient is $0.13(2)$. The $\mathrm{Ru}-\mathrm{Ru}$ distance is

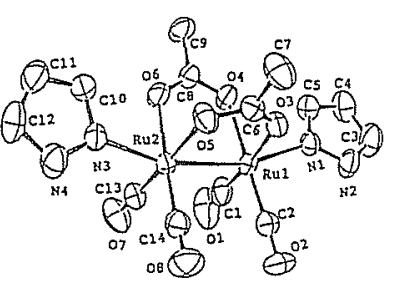
$2.6746(6) \AA$ Both rutheniums have six bonds. The distances of Ru-O range from $2.110(2)$ to $2.136(2) \AA$, those of Ru-C span from $1.822(3)$ to 1.829 (3) $\AA$ and those of Ru-N from 2.203(2) to 2.205(3) $\AA$. The intramolecular hydrogen bonds of $\mathrm{N} 2-\mathrm{H}$....O4 and $\mathrm{N} 4 \mathrm{H} . . . \mathrm{O} 6$ are $2.790(3)$ and $2.774(3) \AA$ respectively, and help stabilize the crystal structure. The conformations and intersections of five member rings will be presented. 